\title{
Organic light-emitting diodes based on charge-neutral Os(II) emitters: generation of saturated red emission with very high external quantum efficiency
}

\author{
Yung-Liang Tung, ${ }^{a}$ Shin-Wun Lee, ${ }^{a}$ Yun Chi, ${ }^{a}{ }^{a}$ Yu-Tai Tao, ${ }^{* b}$ Chin-Hsiung Chien, ${ }^{b}$ Yi-Ming Cheng, ${ }^{c}$ \\ Pi-Tai Chou, ${ }^{* c}$ Shie-Ming Peng ${ }^{c}$ and Chao-Shiuan Liu ${ }^{d}$
}

Received 21st September 2004, Accepted 10th November 2004

First published as an Advance Article on the web 1st December 2004

DOI: $10.1039 / b 414636 k$

The OLED device using $6 \%$ of $\mathrm{Os}(\mathrm{fptz})_{2}\left(\mathrm{PPh}_{2} \mathrm{Me}\right)_{2}$ as the dopant emitter in a CBP host and BPAPF as hole transporting material shows an external quantum efficiency of $15.3 \%$ and luminous efficiency of $21.3 \mathrm{~cd} \mathrm{~A}^{-1}$, power efficiency of $6.3 \mathrm{~lm} \mathrm{~W}^{-1}$ at $20 \mathrm{~mA} \mathrm{~cm}{ }^{-2}$. An even higher external quantum efficiency of $\sim 20 \%$ was achieved at a low current density of $\sim 1 \mathrm{~mA} \mathrm{~cm}^{-2}$.

Since the seminal work of Tang and VanSlyke in electroluminescence (EL) devices using organic materials, ${ }^{1}$ the research activities on organic light-emitting diodes (OLEDs) have made significant progress during the past two decades. The OLEDs of this category continuously attract great interest because of their potential in the development of full color flat-panel displays. In this regard, fabrication of OLEDs with energy efficient, saturated red emission becomes essential, ${ }^{2}$ and this has been achieved by using third-row metal Pt(II)- and Ir(III)-containing phosphorescent dopant emitters, for which the strong spin-orbit coupling effectively promotes the intersystem crossing from singlet excited states to lower triplet emitting states as well as the enhancement of the $\mathrm{T}_{1}-\mathrm{S}_{0}$ transition. ${ }^{3}$ Theoretically, OLEDs with $100 \%$ internal quantum efficiencies may be attained by harnessing both triplet and singlet excitons. ${ }^{4}$ However, for most of the phosphorescent OLEDs, the device quantum efficiency drops rapidly with increasing current density and thus brightness. This is believed to be due to the fact that triplet excitons relax more slowly and the emission inevitably reaches saturation through a quenching mechanism involving triplet-triplet annihilation. ${ }^{5}$ One way to alleviate the problem is to use materials with a shorter triplet radiative lifetime. To achieve this goal, a potential category in point may be Os(II) complexes, ${ }^{6}$ which, in general, possess a shorter triplet-state exciton lifetime ( $\leqslant \mathrm{a}$ few $\mu \mathrm{s}$ ) due to the enhancement of the heavy-metal atom participating in the lowest excited triplet manifolds (either ${ }^{3} \pi-\pi^{*}$, ${ }^{3}$ MLCT or the mixed states). More importantly, owing to its divalent state, the oxidation potential at the Os(II) metal center is significantly lower than that of the $\operatorname{Ir}(\mathrm{III})$ analogues with +3 oxidation state. The higher oxidation potential of the latter makes it less of an ideal center for carrier direct-trapping and recombination. ${ }^{7}$

In this communication, we report the syntheses and characterization of a series of readily sublimable, charge neutral Os(II)

*ychi@mx.nthu.edu.tw (Yun Chi)

ytt@chem.sinica.edu.tw (Yu-Tai Tao)

chop@ntu.edu.tw (Pi-Tai Chou) triazolate complexes, Os(fptz) $)_{2}\left(\mathrm{PPh}_{2} \mathrm{Me}\right)_{2}$ (1) Os(hptz) $)_{2}\left(\mathrm{PPh}_{2} \mathrm{Me}\right)_{2}$ (2) and $\mathrm{Os}(\mathrm{hptz})_{2}\left(\mathrm{PPhMe}_{2}\right)_{2}(3)$, the molecular structures of which are shown in Fig. 1. In contrast to the PLED fabricated using the nonvolatile, ionic Os(II) emitters, ${ }^{6,7}$ remarkably high efficiency in red emission has been achieved by fabricating the OLED devices using a co-deposition technique. In particular, with a device configuration of ITO/BPAPF(40 nm)/CBP : $6 \%$ of $\mathbf{1}(30 \mathrm{~nm}) /$ $\mathrm{BCP}(10 \mathrm{~nm}) / \mathrm{Alq}(30 \mathrm{~nm}) / \mathrm{LiF}(1 \mathrm{~nm}) / \mathrm{Al}(150 \mathrm{~nm})$, an external quantum efficiency of $15.3 \%$ and a luminous efficiency of $21.3 \mathrm{~cd} \mathrm{~A}^{-1}$, power efficiency of $6.3 \mathrm{~lm} \mathrm{~W}^{-1}$ were obtained at $20 \mathrm{~mA} \mathrm{~cm}^{-2}$, yielding CIE coordinates at $x=0.64$ and $y=0.35$. An even higher external quantum efficiency of $\sim 20 \%$ was achieved at a very low current density of $\sim 1 \mathrm{~mA} \mathrm{~cm}{ }^{-2}$. This high efficiency is comparable to that obtained for the best greenemitting $\operatorname{Ir}(\mathrm{III})$ based OLEDs. ${ }^{8}$ A maximum brightness of $\sim 45000 \mathrm{~cd} \mathrm{~m}^{-2}$ was recorded at the driving voltage of $15 \mathrm{~V}$. To our knowledge, this result steps up a major advance for redemitting, small molecule OLEDs fabricated by the co-deposition technique.
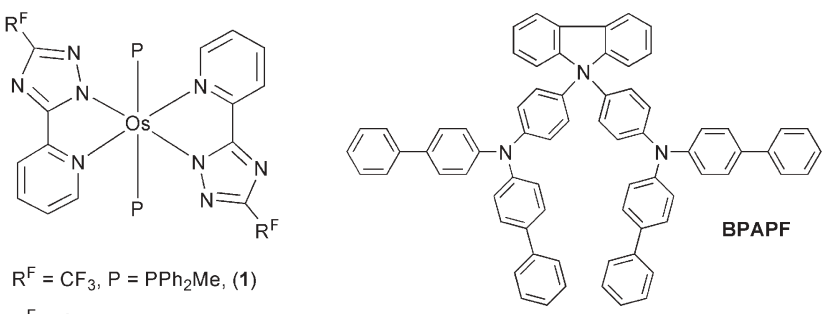

$\mathrm{R}^{\mathrm{F}}=\mathrm{C}_{3} \mathrm{~F}_{7}, \mathrm{P}=\mathrm{PPh}_{2} \mathrm{Me},(2$

$\mathrm{R}^{\mathrm{F}}=\mathrm{C}_{3} \mathrm{~F}_{7}, \mathrm{P}=\mathrm{PPhMe}_{2},(3)$

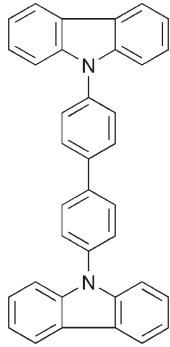

CBP
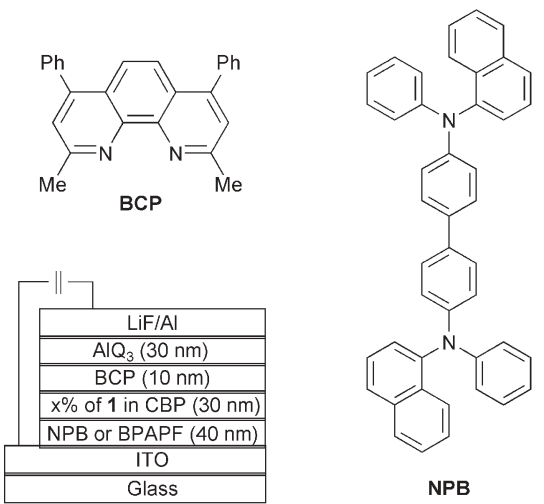

Fig. 1 The molecular structure of the relevant compounds used in this study and configuration of the OLED devices. 
These Os(II) emitting materials are designed by bearing the relatively poor electron-donating pyridyl triazolate anion to increase the stability and to neutralize/balance the +2 charge on the Os(II) metal center, the strategy of which is in a way similar to the previously described pyrazolate complexes. ${ }^{9}$ Synthetic details of the triazole ligands have previously been elaborated. ${ }^{10}$ The pyridyl triazolate ligands are expected to adopt a trans orientation around the Os(II) center. This is confirmed by the observation of a very downfield ortho- $\mathrm{CH}$ signal of the pyridine fragment ( $\delta=10.24-10.12 \mathrm{ppm})$, resulting from the notably strong interligand $\mathrm{N} \cdots \mathrm{H}-\mathrm{C}$ hydrogen bond. ${ }^{9}$ Conversely, in order to tune the phosphorescent emission to the red, phosphine auxiliary ligands are also selected owing to their great electron-donating property (vide infra). Finally, the incorporation of either $\mathrm{CF}_{3}$ or $\mathrm{C}_{3} \mathrm{~F}_{7}$ fluorinated substituents in $\mathbf{1 - 3}$ is essential to reduce the intermolecular interaction, rendering the required volatility to these Os(II) emitting complexes. ${ }^{11}$

The reaction condition was optimized using a one-pot synthetic strategy, which involved the in situ preparation of the dicarbonyl complexes Os(fptz) $)_{2}(\mathrm{CO})_{2}$ and $\mathrm{Os}(\mathrm{hptz})_{2}(\mathrm{CO})_{2}$ from $\mathrm{Os}_{3}(\mathrm{CO})_{12}$, followed by conducting phosphine substitution in presence of $\mathrm{Me}_{3} \mathrm{NO}$. This modified approach circumvents the tedious isolation of the above mentioned intermediates, ${ }^{12}$ gives us the desired Os(II) complexes 1-3 in much improved ( $>70 \%$ ) yields, and hence has a great advantage in scaling up for the industrial application.

The absorption and luminescence spectra of complexes 1-3 in $\mathrm{CH}_{2} \mathrm{Cl}_{2}$ are shown in Fig. 2. The strong absorption bands commonly observed around $400 \mathrm{~nm}$ for $\mathbf{1 - 3}$ are assigned to the spin-allowed ${ }^{1} \pi-\pi^{*}$ transition of the fptz (or hptz) ligands. The next lower energy absorption band around $450 \mathrm{~nm}$ can be ascribed to a spin-allowed metal to ligand charge transfer $\left({ }^{1} \mathrm{MLCT}\right)$ transition, while an equally strong absorption band with peak wavelengths at $543 \mathrm{~nm}\left(\varepsilon=1400 \mathrm{M}^{-1} \mathrm{~cm}^{-1}\right), 545 \mathrm{~nm}$ $\left(\varepsilon=1400 \mathrm{M}^{-1} \mathrm{~cm}^{-1}\right)$ and $550 \mathrm{~nm}\left(\varepsilon=1450 \mathrm{M}^{-1} \mathrm{~cm}^{-1}\right)$ for complexes 1, 2 and 3, respectively, can reasonably be assigned to a state mixing of spin-orbit coupling enhanced ${ }^{3} \pi-\pi^{*}$ and ${ }^{3}$ MLCT transitions. It is also notable that substitution with stronger donor ligands such as $\mathrm{PPhMe}_{2}$ not only causes the spectral red-shift due to the increase of the metal $d \pi$ orbital energy but also increases the

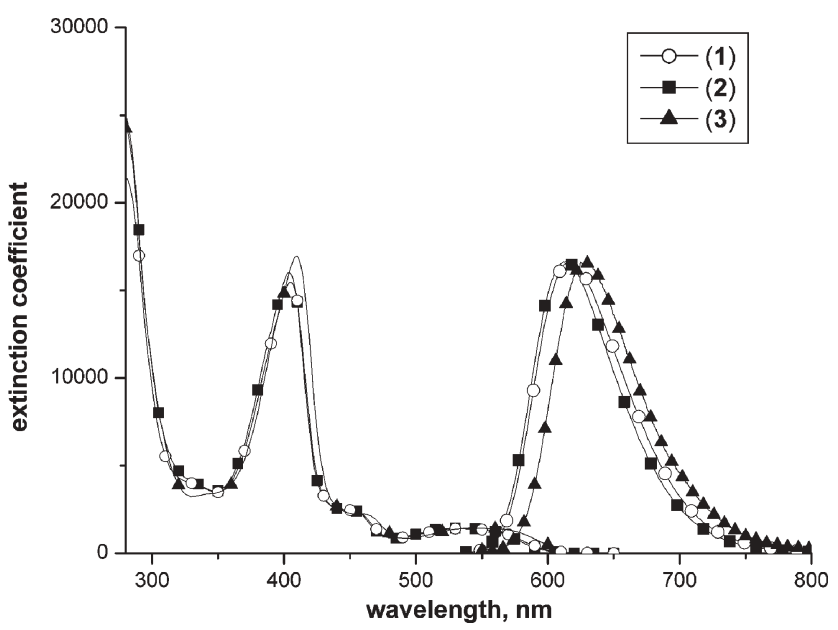

Fig. 2 UV-Vis absorption and normalized emission spectra of $1(-\bigcirc-)$, 2 (-) and 3 (- - -) in $\mathrm{CH}_{2} \mathrm{Cl}_{2}$ at RT; the excitation wavelength: $500 \mathrm{~nm}$. entire transition dipole moment, A similar argument has been proposed to account for the systematic spectral variation of the Os(II) polypyridyl phosphine complexes. ${ }^{13}$

Very intense luminescence was observed for 1-3 with $\lambda_{\max }$ located at $617 \mathrm{~nm}, 614 \mathrm{~nm}$ and $629 \mathrm{~nm}$, respectively, in $\mathrm{CH}_{2} \mathrm{Cl}_{2}$ solution. The significant overlap of the $0-0$ onsets between emission and the lowest energy absorption band, in combination with a broad, structureless spectral feature, leads us to conclude that the phosphorescence originates primarily from the ${ }^{3} \mathrm{MLCT}$ state. ${ }^{14}$ In comparison to 3 bearing $\mathrm{PPhMe}_{2}$ as coordinating ligands, complex 2 with the $\mathrm{PPh}_{2} \mathrm{Me}$ group reveals a $\sim 15 \mathrm{~nm}$ hypsochromic shift in $\lambda_{\max }$ and can qualitatively be rationalized by a decrease of Os(II) $d \pi$ energy level due to the stronger electronwithdrawing strength of an additional phenyl substitution. Table 1 lists the corresponding photophysical data for the studied complexes in both solution and solid phases. The observed lifetimes of $c a$. $0.8-1.0 \mu \mathrm{s}$, in combination with the quantum efficiencies of $0.50-0.76$, lead us to deduce a radiative lifetime of 1.54, 1.23 and $1.62 \mu$ s for $\mathbf{1}, \mathbf{2}$ and $\mathbf{3}$, respectively, in degassed $\mathrm{CH}_{2} \mathrm{Cl}_{2}$. To our knowledge, the radiative lifetimes for 1-3 are considerably shorter than those of most reported red emitting Ir(III) complexes. ${ }^{15}$ In the solid state, the emission maximum for these Os(II) phosphors shifts to the red, possibly due to their molecular packing, and the lifetime falls within the range of 0.2 $0.9 \mu$ s. The emission quantum efficiencies of $\mathbf{1}-\mathbf{3}$ lie in the range $0.21-0.36$ in the solid state. It is notable that the exciton lifetime of $\mathbf{3}$ is about 4.5 times greater than that of $\mathbf{1}$ in solid, implying that the OLED device fabricated using $\mathbf{1}$ should reduce T-T annihilation at the higher driving voltage (vide infra).

Due to its high PL quantum efficiency in the red and excellent redox stability, complex 1 was selected in fabricating a series of multilayer devices of the configuration ITO/HTL(40 nm)/CBP : $\mathbf{1}(30 \mathrm{~nm}) / \mathrm{BCP}(10 \mathrm{~nm}) / \mathrm{AlQ}_{3}(30 \mathrm{~nm}) / \mathrm{LiF}(1 \mathrm{~nm}) / \mathrm{Al}(150 \mathrm{~nm})$, where $\mathrm{CBP}, \mathrm{BCP}$ and $\mathrm{AlQ}_{3}$ stand for $4,4^{\prime}-N, N^{\prime}$-dicarbazolyl-1, $1^{\prime}$-biphenyl, 2,9-dimethyl-4,7-diphenyl-1,10-phenanthroline, and tris(8hydroxyquinolinato) aluminium(III) respectively. Two distinctive hole transporting materials (HTL) were 4,4'-bis[N-(1-naphthyl)$N$-phenylamino]biphenyl (NPB) and 9,9-bis $\{4$-[di-( $p$-biphenyl)aminophenyl] fluorene (BPAPF). ${ }^{16}$ The doping levels of Os(II) complex 1 varied from $6 \%, 12 \%, 20 \%, 50 \%$ to a $100 \%$ neat thin film. Device configurations and the molecular structures of the compounds used in these devices are also shown in Fig. 1, while crucial device performance characteristics are collected in Table 2. Bright red emission was observed for all the concentrations applied, even for the one with a pure layer of the Os(II) emitter. With NPB as HTL, the current-voltage-luminance curves, plotted in Fig. 3a, show a rough trend of decreasing current density with increasing concentrations of $\mathbf{1}$, implying that the phosphorescent dopant sites serve as charge trapping sites. ${ }^{17}$ The EL spectra are given in Fig. 3b. A small amount of emission at $\sim 450 \mathrm{~nm}$, identified as originating from NPB, was observed for the low dopant concentration of $6 \%$. This NPB emission diminished upon increasing the doping concentration to $12 \%$ and higher. Concurrently, a small red shift of the EL spectra was observed with increasing dopant concentrations, from $\lambda_{\max } \sim 620 \mathrm{~nm}$ for the $6 \%$ device to $625 \mathrm{~nm}$ for the neat film device (Fig. 3b), presumably due to the change of the medium polarity. ${ }^{18}$

Interestingly, upon switching the hole-transport layer from NPB to BPAPF, a significant improvement in both luminescence and 
Table 1 Photophysical and electrochemical properties for complexes 1-3

\begin{tabular}{llll}
\hline & $\mathbf{1}$ & $\mathbf{2}$ & $\mathbf{3}$ \\
\hline $\mathrm{UV}_{\mathrm{N}}$ Visible absorption $\varepsilon / \mathrm{nm}^{a}$ & $405(15500), 457(2400), 543(1400)$ & $403(16000), 457(2300), 545(1400)$ & $410(17000), 465(2200), 550(1450)$ \\
$\mathrm{PL} \lambda_{\max }$ & $617(631) \mathrm{nm}$ & $614(618) \mathrm{nm}$ & $629(634) \mathrm{nm}$ \\
$\Phi^{b}$ & $0.62(0.24)$ & $0.76(0.36)$ & $0.50(0.21)$ \\
$\tau_{\mathrm{obs}}^{b}$ & $0.96(0.18) \mu \mathrm{s}$ & $0.94(0.58) \mu \mathrm{s}$ & $0.81(0.91) \mu \mathrm{s}$ \\
$E_{1 / 2}^{\mathrm{ox}}\left[\Delta E_{\mathrm{p}}\right]^{c}$ & $0.12[110]$ & $0.19[130]$ & $0.11[130]$ \\
$E_{1 / 2}^{\text {red }}$ or $E_{\mathrm{cp}}\left[\Delta E_{\mathrm{p}}\right]^{c}$ & $-2.61[120]$ & $-2.78[\mathrm{irr}]$ & $-2.73[\mathrm{irr}]$
\end{tabular}

${ }^{a}{ }_{\varepsilon}$ in $\mathrm{M}^{-1} \mathrm{~cm}^{-1}$. Samples were recorded in $\mathrm{CH}_{2} \mathrm{Cl}_{2}$ at $\mathrm{RT}$ with at least three freeze-pump-thaw cycles. Emission spectra in solution were excited at $500 \mathrm{~nm}$, while an $\mathrm{Ar}^{+}$laser $\left(514 \mathrm{~nm}\right.$ ) was used as an excitation source for the solid sample. ${ }^{b}$ Data in parentheses are measured in solid state at RT. ${ }^{c}$ All potentials are measured in a $0.1 \mathrm{M} \mathrm{TBAPF}_{6}-\mathrm{THF}$ solution and reported in volts using $\mathrm{Fc} / \mathrm{Fc}^{+}$as reference, which is $0.18 \mathrm{~V}$ anodic of $\mathrm{Ag} / \mathrm{AgNO}_{3}$ electrode; $\Delta E_{\mathrm{p}}=E_{\mathrm{ap}}$ (anodic peak potential) $-E_{\mathrm{cp}}$ (cathodic peak potential) and the data is quoted in $\mathrm{mV}$.

Table 2 Performance characteristics for ITO/HTL/CBP : $x \%$ 1/BCP/LiF/Al devices

\begin{tabular}{lllllll}
\hline & Conc. $(\%)$ & Max. lum./cd m & QE $(\%)^{b, c}$ & LE/cd A & PE/lm W ${ }^{-1 b, c}$ & $\lambda_{\text {max }} / \mathrm{nm}^{-1 b}(\mathrm{CIE})^{d}$ \\
\hline With NPB & 6 & $32627(15)$ & $10.71(8.61)$ & $14.28(11.48)$ & $4.37(2.93)$ & $620(0.63,0.35)$ \\
& 12 & $36862(15)$ & $10.77(8.21)$ & $15.15(11.55)$ & $5.99(3.61)$ & $620(0.62,0.34)$ \\
& 20 & $36314(15)$ & $11.46(9.06)$ & $15.24(12.06)$ & $6.04(3.74)$ & $622(0.65,0.35)$ \\
With BPAPF & 50 & $35076(15)$ & $7.31(6.90)$ & $9.02(8.52)$ & $3.47(2.49)$ & $624(0.65,0.34)$ \\
& 100 & $11831(14.5)$ & $2.62(2.44)$ & $2.69(2.49)$ & $1.19(0.84)$ & $626(0.65,0.35)$ \\
& 12 & $45211(15)$ & $15.29(12.17)$ & $21.31(16.97)$ & $6.34(4.23)$ & $618(0.64,0.35)$ \\
& 20 & $34196(15)$ & $14.99(11.02)$ & $19.94(14.67)$ & $6.15(3.76)$ & $620(0.64,0.35)$ \\
& 50 & $25644(15)$ & $13.27(10.30)$ & $17.22(13.36)$ & $4.75(3.12)$ & $622(0.65,0.35)$ \\
& 100 & $20501(15)$ & $7.96(7.38)$ & $9.92(9.19)$ & $2.69(2.12)$ & $622(0.65,0.35)$ \\
& $9049(15)$ & $2.54(2.29)$ & $2.82(2.54)$ & $0.85(0.64)$ & $624(0.65,0.35)$
\end{tabular}

${ }^{a}$ Values in the parentheses are the applied driving voltage. ${ }^{b}$ Data collected under $20 \mathrm{~mA} \mathrm{~cm}{ }^{-2} .{ }^{c}$ Values in the parentheses are the data collected under $100 \mathrm{~mA} \mathrm{~cm}^{-2}$. ${ }^{d}$ Measured at the driving voltage of $8 \mathrm{~V}$.

external quantum efficiency was observed. The EL spectrum is free from BPAPF emission at all dopant concentrations. Such an outcome may be attributed to the higher hole mobility of BPAPF than that of $\mathrm{NPB},{ }^{19}$ so that a shift of the charge recombination area well inside the CBP/Os(II) dopant emitter layer occurs, in view of the similar HOMO energy levels (NPB, $5.2 \mathrm{eV}$; BPAPF, $5.3 \mathrm{eV}$ ) and LUMO energy levels (NPB, $2.2 \mathrm{eV}$; BPAPF, $2.2 \mathrm{eV}$ ) for the two compounds. For comparison, the representative currentvoltage-luminance characteristics for the $6 \%$ dopant device are depicted in Fig. 3c. A very high initial external quantum efficiency of $\sim 20 \%$ and luminous efficiency of $27.8 \mathrm{~cd} \mathrm{~A}^{-1}$ were obtained at $1 \mathrm{~mA} \mathrm{~cm}{ }^{-2}$. Considering the coupling out factor, this is reaching nearly $100 \%$ internal phosphorescence efficiency. ${ }^{8}$ Like other phosphorescent emitters, the efficiencies also witnessed a drop with increasing driving voltage (Fig. 3d). At a driving current of $20 \mathrm{~mA} \mathrm{~cm}^{-2}$, the external quantum efficiency is $15.3 \%$ and luminous efficiency is $21.3 \mathrm{~cd} \mathrm{~A}^{-1}$, whereas at $100 \mathrm{~mA} \mathrm{~cm}^{-2}$, the efficiencies remain $12.2 \%$ and $17 \mathrm{~cd} \mathrm{~A}^{-1}$ respectively. However, it is noted that the decreasing trend in the quantum efficiency/power efficiency versus current density is slower than those reported for the triplet-state emitters. ${ }^{2}$ The key difference is plausibly due to the remarkably short radiative lifetime ( $\sim 0.75 \mu$ s for $\mathbf{1}$ in solid), which significantly reduces the triplet-triplet annihilation.

In conclusion, a very efficient synthetic method for the charge neutral Os(II) emitters has been discovered and highly efficient, saturated red color, phosphorescent OLEDs are achieved by codeposition of the charge neutral Os(II) triazolate complexes with CBP host as the emitting layer. The results demonstrate for the first time the generation of saturated red emission with external quantum efficiency up to $20 \%$ among the organometallic emitters composing the third-row Os(II), Ir(III) and Pt(II) elements. ${ }^{3,6}$ In addition to the color tuning that should gain considerable interest, other basic photophysical properties, such as the phosphorescence lifetime of the designed Os(II) complexes, are also adjustable through modification of their ancillary coordination ligands to optimize the performance of the triplet-exciton driven OLEDs.

$\left[\mathrm{Os}(\mathrm{fptz})_{2}\left(\mathrm{PPh}_{2} \mathrm{Me}\right)_{2}\right]$ (1) was prepared as follows. A $50 \mathrm{~mL}$ reaction flask was charged with 3-trifluoromethyl-5-(2-pyridyl)1,2,4-triazole (fptzH, $298 \mathrm{mg}, 1.39 \mathrm{mmol}$ ), pulverized $\mathrm{Os}_{3}(\mathrm{CO})_{12}$ (200 mg, $0.22 \mathrm{mmol}$ ), and $20 \mathrm{~mL}$ of anhydrous diethylene glycol monoethyl ether (DGME). The mixture was heated at $180-190{ }^{\circ} \mathrm{C}$ for $24 \mathrm{~h}$. After that, the temperature was lowered to $\sim 150{ }^{\circ} \mathrm{C}$, freshly sublimed $\mathrm{Me}_{3} \mathrm{NO}(120 \mathrm{mg}, 1.59 \mathrm{mmol})$ dissolved in $12 \mathrm{~mL}$ DGME was added and stirring was continued for $5 \mathrm{~min}$. Finally, $\mathrm{PPh}_{2} \mathrm{Me}(592 \mu \mathrm{L}, 3.18 \mathrm{mmol})$ was injected into the mixture. In the meantime, the temperature of solution was raised to $190{ }^{\circ} \mathrm{C}$. After $12 \mathrm{~h}$, the reaction was stopped. The solvent was evaporated under vacuum, and the residue was washed with distilled water $(20 \mathrm{~mL} \times 2)$ to remove the remaining $\mathrm{Me}_{3} \mathrm{NO}$. Purification by silica gel column chromatography (with EA-hexane $=1: 1$ as eluent), followed by recrystallization from a mixture of EA and hexane at room temperature, yielded a bright red crystalline solid (504 $\mathrm{mg}, 0.50 \mathrm{mmol}$ ) in $75 \%$ yield.

Spectral data: MS (FAB, $\left.{ }^{192} \mathrm{Os}\right): m / z 1018\left(\mathrm{M}^{+}\right), 818\left(\mathrm{M}^{+}-\right.$ $\left.\mathrm{PPh}_{2} \mathrm{Me}\right), 618\left(\mathrm{M}^{+}-2 \mathrm{PPh}_{2} \mathrm{Me}\right) .{ }^{1} \mathrm{H} \mathrm{NMR}\left(400 \mathrm{MHz}, \mathrm{d}_{6^{-}}\right.$ acetone): $\delta 10.26\left(\mathrm{~d}, 2 \mathrm{H}, J_{\mathrm{HH}}=6.8 \mathrm{~Hz}\right), 7.54\left(\mathrm{ddd}, 2 \mathrm{H}, J_{\mathrm{HH}}=6.8\right.$, 7.6, $0.8 \mathrm{~Hz}), 7.29\left(\mathrm{~d}, 2 \mathrm{H}, J_{\mathrm{HH}}=7.6,0.8 \mathrm{~Hz}\right), 7.21(\mathrm{ddd}, 2 \mathrm{H}$, $\left.J_{\mathrm{HH}}=7.6,6.8,0.8 \mathrm{~Hz}\right), 7.24-7.10(\mathrm{~m}, 4 \mathrm{H}), 7.00(\mathrm{t}, 4 \mathrm{H}$, $\left.J_{\mathrm{HH}}=7.6 \mathrm{~Hz}\right), 6.92\left(\mathrm{t}, 4 \mathrm{H}, J_{\mathrm{HH}}=7.6 \mathrm{~Hz}\right), 6.89-6.84(\mathrm{~m}, 4 \mathrm{H})$, 6.69-6.60 (m, 4H), $1.24\left(\mathrm{t}, 6 \mathrm{H}, J_{\mathrm{HP}}=3.4 \mathrm{~Hz}, \mathrm{CH}_{3}\right)$. Anal. Calcd. for $\mathrm{C}_{42} \mathrm{H}_{34} \mathrm{~F}_{6} \mathrm{~N}_{8} \mathrm{OsP}_{2}$ : C, 49.60; N, 11.02; H, 3.37. Found: C, 49.61; $\mathrm{N}, 10.98 ; \mathrm{H}, 3.50$. 
(a) I-V-B figure of NPB/CBP:X\% 1/BCP/Alq/LiF/AI

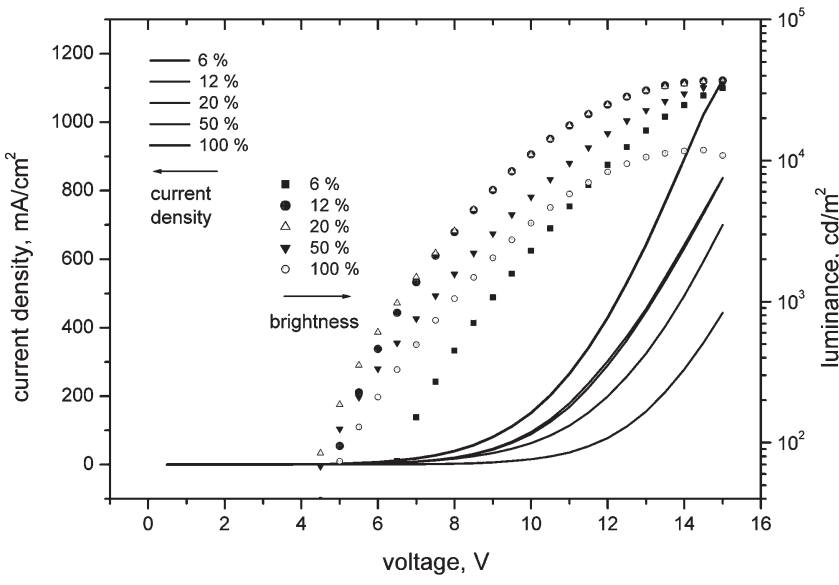

(c) I-V-B figure of BPAPF/CBP:X\% 1/BCP/Alq/LiF/Al

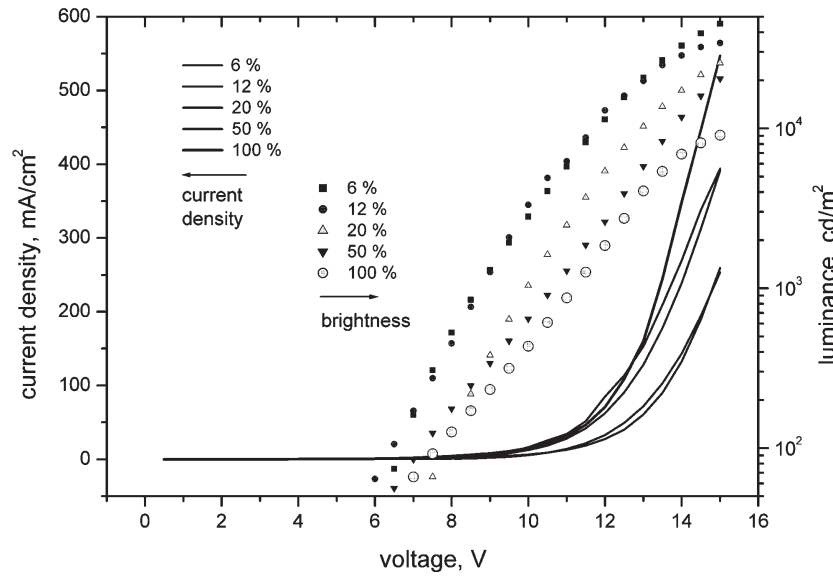

(b) EL spectra of NPB/X\% 1 in CBP/BCP/Alq/LiF/Al at $8 \mathrm{~V}$

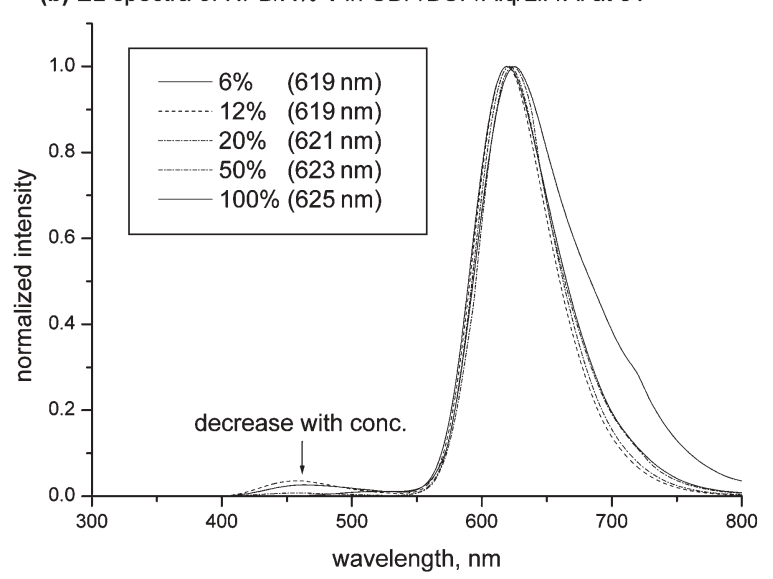

(d) Q.E. and L.E. of BPAPF/CBP:6\% 1/BCP/Alq/LiF/AI

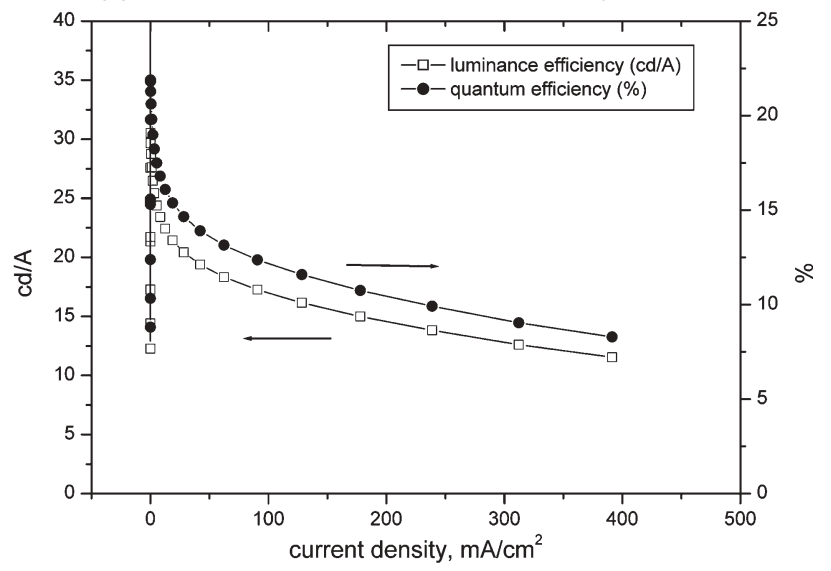

Fig. 3 (a) $I-V-L$ characteristics of the devices based on 1 with NPB as HTL, (b) EL spectra of devices with NPB as HTL, as a function of doping concentration, (c) $I-V-L$ characteristics of the devices based on $\mathbf{1}$ with BPAPF as HTL and (d) external quantum efficiency and luminous efficiency as a function of current density for device ITO/BPAPF/CBP : $6 \%$ 1/BCP/LiF/Al.

$\left[\mathrm{Os}(\mathrm{hptz})_{2}\left(\mathrm{PPh}_{2} \mathrm{Me}\right)_{2}\right]$ (2) and $\left[\mathrm{Os}(\mathrm{hptz})_{2}\left(\mathrm{PPhMe}_{2}\right)_{2}\right]$ (3) were prepared as follows. The synthetic procedures are essentially identical to those for complex 1, using a similar molecular ratio of 3-heptafluoropropyl-5-(2-pyridyl) 1,2,4-triazole (hppzH), powdery $\mathrm{Os}_{3}(\mathrm{CO})_{12}$, freshly sublimed $\mathrm{Me}_{3} \mathrm{NO}$ and the phosphine ligands. The orange-red complex $\mathbf{2}$ and bright red complex $\mathbf{3}$ were obtained in $73 \%$ and $70 \%$ yields, respectively.

Spectral data of 2: MS (FAB, $\left.{ }^{192} \mathrm{Os}\right): \mathrm{m} / z 1219\left(\mathrm{M}^{+}\right), 1019\left(\mathrm{M}^{+}-\right.$ $\left.\mathrm{PPh}_{2} \mathrm{Me}\right), 818\left(\mathrm{M}^{+}-2 \mathrm{PPh}_{2} \mathrm{Me}\right) .{ }^{1} \mathrm{H}$ NMR $(400 \mathrm{MHz}$, $\mathrm{d}_{6}$-acetone): $\delta 10.24\left(\mathrm{~d}, 2 \mathrm{H}, J_{\mathrm{HH}}=6.8 \mathrm{~Hz}\right), 7.49(\mathrm{dd}, 2 \mathrm{H}$, $\left.J_{\mathrm{HH}}=6.8,7.6 \mathrm{~Hz}\right), 7.30\left(\mathrm{~d}, 2 \mathrm{H}, J_{\mathrm{HH}}=7.6 \mathrm{~Hz}\right), 7.18-7.14(\mathrm{~m}, 4 \mathrm{H})$, $7.10-7.03(\mathrm{~m}, 10 \mathrm{H}), 6.88\left(\mathrm{t}, 4 \mathrm{H}, J_{\mathrm{HH}}=7.4 \mathrm{~Hz}\right), 6.59-6.55(\mathrm{~m}, 4 \mathrm{H})$, $1.22\left(\mathrm{t}, 6 \mathrm{H}, J_{\mathrm{HP}}=3.2 \mathrm{~Hz}, \mathrm{CH}_{3}\right) \cdot{ }^{19} \mathrm{~F}$ NMR $(470 \mathrm{MHz}$, $\mathrm{d}_{6}$-acetone): $\delta-122.6(\mathrm{~s}, 4 \mathrm{~F}),-109.7\left(\mathrm{q}, 4 \mathrm{~F}, J_{\mathrm{FF}}=10.0 \mathrm{~Hz}\right)$, $-79.8\left(\mathrm{t}, 6 \mathrm{~F}, J_{\mathrm{FF}}=10.0 \mathrm{~Hz}\right){ }^{31} \mathrm{P}$ NMR $\left(202 \mathrm{MHz}, \mathrm{d}_{6}\right.$-acetone): $\delta-18.2$ (s). Anal. Calcd for $\mathrm{C}_{46} \mathrm{H}_{34} \mathrm{~F}_{14} \mathrm{~N}_{8} \mathrm{OsP}_{2}$ : C, 45.40; N, 9.21; H, 2.82. Found: C, 45.41; N, 9.27; H, 2.98.

Spectral data of 3: MS (FAB, $\left.{ }^{192} \mathrm{Os}\right): m / z 1095\left(\mathrm{M}^{+}\right), 957\left(\mathrm{M}^{+}-\right.$ $\left.\mathrm{PPhMe}_{2}\right), 8618\left(\mathrm{M}^{+}-2 \mathrm{PPhMe}_{2}\right) .{ }^{1} \mathrm{H}$ NMR $(400 \mathrm{MHz}$, $\mathrm{d}_{6}$-acetone): $\delta 10.12\left(\mathrm{~d}, 2 \mathrm{H}, J_{\mathrm{HH}}=6.4 \mathrm{~Hz}\right), 7.73(\mathrm{dd}, 2 \mathrm{H}$, $\left.J_{\mathrm{HH}}=6.4,7.4 \mathrm{~Hz}\right), 7.68-7.65(\mathrm{~m}, 2 \mathrm{H}), 7.20\left(\mathrm{ddd}, 2 \mathrm{H}, J_{\mathrm{HH}}=7.4\right.$, $6.4,1.6 \mathrm{~Hz}), 7.08\left(\mathrm{t}, 2 \mathrm{H}, J_{\mathrm{HH}}=7.6 \mathrm{~Hz}\right), 6.90\left(\mathrm{t}, 4 \mathrm{H}, J_{\mathrm{HH}}=7.6 \mathrm{~Hz}\right)$, $6.38-6.33(\mathrm{~m}, 4 \mathrm{H}), 0.86\left(\mathrm{t}, 6 \mathrm{H}, J_{\mathrm{HP}}=3.2 \mathrm{~Hz}, \mathrm{CH}_{3}\right), 0.61(\mathrm{t}, 6 \mathrm{H}$,
$\left.J_{\mathrm{HP}}=3.2 \mathrm{~Hz}, \mathrm{CH}_{3}\right) \cdot{ }^{19} \mathrm{~F}$ NMR $\left(470 \mathrm{MHz}, \mathrm{d}_{6}\right.$-acetone): $\delta-126.1$ $(\mathrm{s}, 4 \mathrm{~F}),-110.1\left(\mathrm{q}, 4 \mathrm{~F}, J_{\mathrm{FF}}=8.3 \mathrm{~Hz}\right),-80.0\left(\mathrm{t}, 6 \mathrm{~F}, J_{\mathrm{FF}}=8.3 \mathrm{~Hz}\right)$. ${ }^{31} \mathrm{P}$ NMR (202 MHz, $\mathrm{d}_{6}$-acetone): $\delta-22.1$ (s). Anal. Calcd for $\mathrm{C}_{36} \mathrm{H}_{30} \mathrm{~F}_{14} \mathrm{~N}_{8} \mathrm{OsP}_{2}$ : C, 39.57; N, 10.25; H, 2.77. Found: C, 39.43; N, 10.20; H, 2.90.

Photophysical measurements were taken as follows. Steady-state absorption, emission and phosphorescence lifetime measurements both in solution and solid have been elaborated in our previous reports. ${ }^{9,20}$ For measuring quantum yields in the solid state, an integrating sphere (Labsphere) was applied, in which the solid sample film was prepared via a vapor deposition method and was excited by a $514 \mathrm{~nm} \mathrm{Ar}^{+}$laser line. The resulting luminescence was acquired by an intensified charge-coupled detector for subsequent quantum yield analyses. ${ }^{21}$

OLED fabrication and data measurement were performed as follows. BCP was purchased from Aldrich and used as received. $\mathrm{AlQ}_{3}, \mathrm{NPB}$ and BPAPF were synthesized according to literature procedures, and were sublimed twice prior to use. Patterned ITO substrates with an effective device area of $3.14 \mathrm{~mm}^{2}$ were cleaned as described in a previous report. ${ }^{22} \mathrm{~A} 40 \mathrm{~nm}$ thick film of BPAPF or NPB was first deposited as the hole transport layer (HTL). The light-emitting layer $(30 \mathrm{~nm})$ was then deposited by co-evaporating the CBP host and the phosphorescent dopant from two 
independent sources, with both deposition rates being controlled with two independent quartz crystal oscillators. A $10 \mathrm{~nm}$ thick $\mathrm{BCP}$ as a hole and exciton blocking layer (HBL) and $30 \mathrm{~nm}$ thick $\mathrm{AlQ}_{3}$ as an electron transport layer were then deposited sequentially. A thin layer of $\mathrm{LiF}(1 \mathrm{~nm})$ and a thick layer of $\mathrm{Al}$ $(150 \mathrm{~nm})$ were followed as the cathode. The current-voltageluminance of the devices was measured in ambient conditions with a Keithley 2400 Source meter and a Newport 1835C Optical meter equipped with $818 \mathrm{ST}$ silicon photodiode.

\section{Acknowledgements}

We thank the National Science Council of Taiwan, ROC for the financial supports (NSC 93-2113-M-007-012) and (NSC 93-ET-7-007-003).

\author{
Yung-Liang Tung, ${ }^{a}$ Shin-Wun Lee, ${ }^{a}$ Yun Chi, ${ }^{* a}$ Yu-Tai Tao, ${ }^{* b}$ \\ Chin-Hsiung Chien, ${ }^{b}$ Yi-Ming Cheng, ${ }^{c}$ Pi-Tai Chou, ${ }^{* c}$ Shie-Ming Peng ${ }^{c}$ \\ and Chao-Shiuan Liu $^{d}$ \\ ${ }^{a}$ Department of Chemistry, National Tsing Hua University, Hsinchu, \\ 300,Taiwan.E-mail:ychi@mx.nthu.edu.tw \\ ${ }^{b}$ Institute of Chemistry, Academia Sinica, Taipei, 115, Taiwan. \\ E-mail:ytt@chem.sinica.edu.tw \\ ${ }^{c}$ Department of Chemistry and Instrumentation Center, National Taiwan \\ University,Taipei,106,Taiwan.E-mail: chop@ntu.edu.tw \\ ${ }^{d}$ Department of Chemistry, SooChow University, Taipei, 111, Taiwan
}

\section{Notes and references}

1 C. W. Tang and S. A. VanSlyke, Appl. Phys. Lett., 1987, 51, 913.

2 (a) C. Adachi, M. A. Baldo, S. R. Forrest, S. Lamansky, M. E. Thompson and P. C. Kwong, Appl. Phys. Lett., 2001, 78, 1622; (b) Y.-J. Su, H.-L. Huang, C.-L. Li, C.-H. Chien, Y.-T. Tao, P.-T. Chou, S. Satta and R.-S. Liu, Adv. Mater., 2003, 15, 884; (c) A. Tsuboyama, H. Iwawaki, M. Furugori, T. Mukaide, J. Kamatani, S. Igawa, T. Moriyama, S. Miura, T. Takiguchi, S. Okada, M. Hoshino and K. Ueno, J. Am. Chem. Soc., 2003, 125, 12971; (d) C. Jiang, W. Yang, J. Peng, S. Xiao and Y. Cao, Adv. Mater., 2004, 16, 537.

3 (a) S. Lamansky, P. Djurovich, D. Murphy, F. Abdel-Razzaq, H.-E. Lee, C. Adachi, P. E. Burrows, S. R. Forrest and M. E. Thompson, J. Am. Chem. Soc., 2001, 123, 4304; (b) J. Brooks, Y. Babayan, S. Lamansky, P. I. Djurovich, I. Tsyba, R. Bau and M. E. Thompson, Inorg. Chem., 2002, 41, 3055.

4 M. A. Baldo, D. F. O’Brien, Y. You, A. Shoustikov, S. Sibley, M. E. Thompson and S. R. Forrest, Nature, 1998, 395, 151.

5 M. A. Baldo, C. Adachi and S. R. Forrest, Phys. Rev. B, 2000, 62, 10967.
6 (a) X. Jiang, A. K.-Y. Jen, B. Carlson and L. R. Dalton, Appl. Phys. Lett., 2002, 80, 713; (b) S. Bernhard, X. Gao, G. G. Malliaras and H. D. Abruna, Adv. Mater., 2002, 14, 433; (c) X. Jiang, A. K. Y. Jen, B. Carlson and L. R. Dalton, Appl. Phys. Lett., 2002, 81, 3125; (d) H.-J. Su, F.-I. Wu, C.-F. Shu, Y.-L. Tung, Y. Chi and G.-H. Lee, J. Polym. Sci., Part A: Polym. Chem., 2005, DOI: 10.1002/pola.2059.

7 (a) B. Carlson, G. D. Phelan, W. Kaminsky, L. Dalton, X. Z. Jiang, S. Liu and A. K.-Y. Jen, J. Am. Chem. Soc., 2002, 124, 14162; (b) J. H. Kim, M. S. Liu, A. K.-Y. Jen, B. Carlson, L. R. Dalton, C.-F. Shu and R. Dodda, Appl. Phys. Lett., 2003, 83, 776.

8 (a) C. Adachi, M. A. Baldo, M. E. Thompson and S. R. Forrest, J. Appl. Phys., 2001, 90, 5048; (b) M. Ikai, S. Tokito, Y. Sakamoto, T. Suzuki and Y. Taga, Appl. Phys. Lett., 2001, 79, 156.

9 Y.-L. Tung, P.-C. Wu, C.-S. Liu, Y. Chi, J.-K. Yu, Y.-H. Hu, P.-T. Chou, S.-M. Peng, G.-H. Lee, Y. Tao, A. J. Carty, C.-F. Shu and F.-I. Wu, Organometallics, 2004, 23, 3745.

10 (a) P. Passaniti, W. R. Browne, F. C. Lynch, D. Hughes, M. Nieuwenhuyzen, P. James, M. Maestri and J. G. Vos, J. Chem. Soc., Dalton Trans., 2002, 1740; (b) M. H. Klingele and S. Brooker, Coord. Chem. Rev., 2003, 241, 119; (c) J. G. Haasnoot, Coord. Chem. Rev., 2000, 200-202, 131; (d) J.-K. Yu, Y.-H. Hu, Y.-M. Cheng, P.-T. Chou, S.-M. Peng, G.-H. Lee, Y.-L. Tung, S.-W. Lee, Y. Chi and C.-S. Liu, Chem Eur. J., 2004, DOI: 10.1002/chem.200400598.

11 (a) Y. Wang, N. Herron, V. V. Grushin, D. LeCloux and V. Petrov, Appl. Phys. Lett., 2001, 79, 449; (b) V. V. Grushin, N. Herron, D. D. LeCloux, W. J. Marshall, V. A. Petrov and Y. Wang, Chem. Commun., 2001, 1494.

12 P.-C. Wu, J.-K. Yu, Y.-H. Song, Y. Chi, P.-T. Chou, S.-M. Peng and G.-H. Lee, Organometallics, 2003, 22, 4938.

13 (a) E. M. Kober, B. P. Sullivan, W. J. Dressick, J. V. Caspar and T. J. Meyer, J. Am. Chem. Soc., 1980, 102, 7383; (b) E. M. Kober, J. V. Caspar, R. S. Lumpkin and T. J. Meyer, J. Phys. Chem., 1986, 90, 3722.

14 A. Vlcek, Jr., Coord. Chem. Rev., 1998, 177, 219

15 Y.-H. Song, S.-J. Yeh, C.-T. Chen, Y. Chi, C.-S. Liu, J.-K. Yu, Y.-H. Hu, P.-T. Chou, S.-M. Peng and G.-H. Lee, Adv. Funct. Mater., 2004, DOI: 10.1002/adfm200400137.

16 C.-W. Ko and Y.-T. Tao, Synth. Met., 2002, 126, 37.

17 X. Gong, J. C. Ostrowski, D. Moses, G. C. Bazan and A. J. Heeger, Adv. Funct. Mater., 2003, 13, 439.

18 V. Bulovic, R. Deshpande, M. E. Thompson and S. R. Forrest, Chem. Phys. Lett., 1999, 308, 317.

19 The hole mobility of BPAPF was estimated to be an order of magnitude higher than that of NPB from time-of-flight measurement, unpublished results.

20 P.-T. Chou, W.-S. Yu, Y.-M. Cheng, S.-C. Pu, Y.-C. Yu, Y.-C. Lin, C.-H. Huang and C.-T. Chen, J. Phys. Chem. A., 2004, 108, 6487.

21 J.-C. de Mello, H.-F. Wittmann and R.-H. Friend, Adv. Mater., 1997, 9, 230.

22 W.-S. Huang, J. T. Lin, C.-H. Chien, Y.-T. Tao, S.-S. Sun and Y.-S. Wen, Chem. Mater., 2004, 16, 2480. 